\title{
Da "forma" à "memória". Das casas sem sítio para a cidade como determinante nos projetos de Peter Eisenman
}

\author{
From "form" to "memory." From houses of no site to the city as a \\ determinant in Peter Eisenman's projects
}

\begin{abstract}
De la "forma" a la "memoria". De las casas sin sitio a la ciudad como determinante en los proyectos de Peter Eisenman
\end{abstract}

Recebido em 26/04/2021 Aceito em 08/12/2021

CARVALHO, Carolina Ferreira de

Programa de Pós-graduação em Arquitetura, Faculdade de Arquitetura e Urbanismo, Universidade Federal do Rio de Janeiro. Rio de Janeiro, Rio de Janeiro, Brasil. carolina.carvalho@fau.ufrj.br ORCID: 0000-0003-0059-3611 


\title{
Resumo
}

Ao longo dos anos, a abordagem de Peter Eisenman frente a suas críticas à arquitetura vigente foi se modificando. No recorte englobado por este artigo, no entanto, sua busca nunca deixou de ser a autonomia da arquitetura, partindo, inicialmente, do suporte na arte conceitual e na linguística, e, posteriormente, migrando para as interpretações pós-estruturalistas. A crítica que antes se configurava em uma arquitetura desprovida de referenciais externos depois passa a ter no contexto urbano o grande agente da concepção de seus projetos. Assim, o presente artigo visa apresentar a arquitetura crítica de Eisenman e discutir como esta deixa de ser tão excludente de seus elementos contextuais para passar a se relacionar à memória dos locais em que está inserida. Para tanto, buscou-se a leitura de autores que influenciaram o trabalho de Eisenman, bem como de textos do próprio arquiteto e de seus críticos, na intenção de melhor compreender o ambiente e as reflexões que propiciaram tais produções arquitetônicas, além da transição de uma para a outra. Neste estudo, foram identificadas as principais diferenças entre ambas atuações, mas também concluiu-se a existência de uma conversão no que se refere ao afastamento do observador/usuário das duas diferentes séries de projeto abordadas.

Palavras-Chave: Arquitetura pós-moderna, arquitetura conceitual, Peter Eisenman, cidades de escavação artificial, forma, memória.

\begin{abstract}
Over the years, Peter Eisenman's approach to his criticisms of current architecture has changed. In the scope of this article, however, the search for it has never ceased to be the architecture's autonomy, starting, initially, from the support in conceptual art and linguistics, and, later, migrating to post-structuralist interpretations. The criticism that was previously configured in an architecture devoid of external references, then comes to have in the urban context the great agent of the design of his projects. Thus, this article aims to present Eisenman's critical architecture and discuss how it ceases to be so exclusive of its contextual elements and starts to relate to the memory of the places in which it is inserted. Therefore, we sought to read authors who influenced Eisenman's work, as well as texts by the architect himself and his critics, with the intention of better understanding the environment and the reflections that provided such architectural productions, in addition to the transition from the first one to the second one. In this study, the main differences between both actions were identified, but it was also concluded the existence of a conversion regarding the distancing of the observer/user from the two different series of projects.
\end{abstract}

Key-Words: Post-modern architecture, conceptual architecture, Peter Eisenman, cities of artificial excavation, form, memory.

\section{Resumen}

A lo largo de los años, el enfoque de Peter Eisenman a sus críticas a la arquitectura actual ha cambiado. En el ámbito de este artículo, sin embargo, su búsqueda nunca ha dejado de ser la autonomía de la arquitectura, partiendo, inicialmente, del soporte en el arte conceptual y lingüístico, y, posteriormente, migrando hacia interpretaciones posestructuralistas. La crítica que solía configurarse en una arquitectura desprovista de referenciales externos, pasa entonces a tener en el contexto urbano al gran agente de la concepción de sus proyectos. Así, este artículo pretende presentar la arquitectura crítica de Eisenman y discutir cómo deja de ser tan excluyente de sus elementos contextuales y pasa a relacionarse con la memoria de los lugares en los que se inserta. Para ello, se buscó la lectura de autores que influyeron en la obra de Eisenman, así como textos del propio arquitecto y de sus críticos, con la intención de comprender mejor el entorno y las reflexiones que brindaban tales producciones arquitectónicas, además de la transición de un al otro. En este estudio, fueran identificadas las principales diferencias entre ambas acciones, pero también se concluyó la existencia de una conversión referente al distanciamiento del observador/usuario de las dos series de proyectos diferentes abordados.

Palabras clave: Arquitectura pos-moderna, arquitectura conceptual, Peter Eisenman, ciudades de excavación ficticia, forma, memoria. 


\section{Introdução}

O trabalho do arquiteto Peter Eisenman costuma ser associado, comumente, à fase na qual sua investigação consiste em alcançar uma arquitetura conceitual, isto é, que se apresenta como desvinculada e independente de sítio, história, ou mesmo cliente. Em projeto, isso se configura nas tão famosas casas brancas geradas por formas geométricas simples - justificável, em grande medida, pela influências das vanguardas europeias do início do século XX - e suas representações em projeções isométricas.

Contudo, sua atuação não se limita a essa abordagem, muito embora algumas de suas críticas permaneçam até o fim do século. O presente estudo visa apresentar duas delas: uma mais focada na interioridade do objeto arquitetônico e a outra, ao contrário, que toma elementos da história e da cidade como determinantes de suas decisões projetuais. Mas ambas voltadas para a questão da autonomia disciplinar.

Tais maneiras de se conceber a arquitetura partem de um contexto que se estende de meados da década de 1960 até o final dos anos 1980, o qual lida com a revisão e a crítica ao Movimento Moderno, principalmente no que se refere à exaltação do mesmo aos pensamentos funcionalista $e$ positivista, aliados, também, da concepção de determinismo histórico. A absorção da arquitetura moderna pelo mercado imobiliário é outra grande fonte de questionamento, como afirma o arquiteto, historiador e crítico de arquitetura Alan Colquhoun (1983) sobre a distorção dos valores utópicos das vanguardas artísticas do início do século XX, impulsionantes das demais manifestações modernas, mas desvinculadas do movimento ao longo do seu processo de capitalização.

Jonas Delecave (2015), em sua dissertação, ressalta que este momento é característico da transição de uma sociedade industrial para a pós-industrial, fazendo com que a mentalidade da época deixasse de ser focada na produção e no entusiasmo tecnológico para se voltar ao consumo e à exploração da imagem. Por conseguinte, a arquitetura também passa a ser tratada como o que K. Michael Hays (2010, p. 68, tradução nossa) chama de uma "unidade de troca visual". Isto é, uma comercialização da arquitetura através de sua característica figurativa, imagética.

Hays (2010) levanta, então, que a frustração com os rumos da disciplina levaria alguns arquitetos a teorizarem e conceberem seus projetos despidos função ou mesmo de sensualidade - que pode ser lida como uma propriedade da arquitetura de ser aprazível visualmente, agradável aos olhos do observador ou usuário -, em oposição ao apelo imagético responsável por reificar as formas arquitetônicas. As duas práticas apresentadas neste artigo são algumas das maneiras utilizadas por arquitetos da época no embate com a transformação da arquitetura em um objeto de consumo, e ambas protagonizadas por Peter Eisenman, figura atuante e polêmica desse debate.

\section{Forma}

A discussão sobre a autonomia da arquitetura no período pós-moderno foi bastante motivada pelo fervor da arte conceitual na cena norte-americana dos anos de 1960. Na mesma época, surge também uma intensa onda de teorias linguísticas - podendo-se delas destacar o Estruturalismo, mais forte na Europa, e a formulação da Gramática Gerativa nos Estados Unidos -, que passam a ser aplicadas à explicação e à análise de diversos campos do saber. De acordo com Andrés Passaro (2009), a arquitetura conceitual teria surgido, primeiramente, pela influência dos mecanismos da arte conceitual e, posteriormente, aproximado-se do discurso estruturalista e suas ferramentas linguísticas.

O momento de maior destaque para essa concepção da arquitetura é em uma reunião do CASE (Conference of Architects for the Study of the Environment) juntamente com o IAUS (Institute of Architecture and Urban Studies) - ambos sediados em Nova York -, realizada no MoMA e intitulada de Five Architects, com a posterior publicação homônimas em formato de catálogo em 1972. A exposição apresentava os trabalhos dos New York Five, grupo composto por Peter Eisenman, John Hejduk, Richard Meier, Michael Graves e Charles Gwathmey, todos arquitetos americanos e que partilhavam do interesse pela discussão formal das vanguardas europeias (DELECAVE, 2015).

Eles também eram conhecidos como "The Whites", justamente devido à preferência por expor seus projetos em planos brancos. Suas principais características podem ser resumidas na representação 
de projetos residenciais em perspectivas ortogonais - capazes de afastar ao máximo o caráter de subjetividade das imagens, ao contrário do que acontece com as perspectivas cônicas, que se aproximam da visão humana. Tal efeito propõe uma espécie de "negação do sujeito" (PASSARO, 2009, p.144) a partir do uso de formas geométricas simples e muitas vezes puristas, consequência do já mencionado apreço pelas características plásticas ${ }^{1}$ inovadoras das vanguardas artísticas do início do século XX.

Esses pontos, no entanto, são os únicos que aproximam as investigações dos cinco arquitetos (DELECAVE, 2015), já que as experimentações de cada um possuíam objetivos diferentes e recorriam a ferramentas distintas. O uso da semiologia é uma delas. Enquanto alguns arquitetos exploravam os recurso semânticos da ciência linguística, como Michael Graves, outros estavam muito mais preocupados com seus mecanismos sintáticos e a maneira pela qual podiam ser explorados na arquitetura, tendo como exemplo Peter Eisenman (LUCENA, 2010).

Em todo caso, esses projetos são frutos de densas análises formais, buscando cada vez mais a interioridade da arquitetura, sua tautologia. Suas representações ortogonais pretendem elevar ao máximo o nível de abstração dos projetos, chegando a desvinculá-los do mundo físico. Segundo Hays (2010, p. 55), no caso de Eisenman, a complexidade das formas e a maneira como o arquiteto utiliza a sobreposição de estruturas destituídas de seu papel estrutural - devido a um excesso de vigas e pilares que apresentam apenas como elementos de intervenção, desprovidos do papel de sustentação - são estratégias para causar uma desfamiliarização do observador para com a arquitetura; uma espécie de estranhamento, no intuito de destacar o papel do processo gerador da forma, além de aniquilar seus atributos sensuais. O efeito de estranhamento gera uma espécie de repulsa em vez de atração do usuário pela forma arquitetônica no intuito de deslocar sua atenção do produto final (normalmente dotado de uma beleza harmônica, compositiva) para o desenvolvimento que, quando interrompido, gera a forma ali presente.

As casas de Eisenman, mesmo quando de fato construídas, não são atreladas a um terreno, isto é, não respondem a questões climáticas, topográficas ou mesmo programáticas. Elas nem sequer possuem nome, sendo sempre intituladas pelo seu número serial (House I, House II, etc.). São desligadas de qualquer referente externo ou observação individual - o que inclui seus donos. As únicas preocupações do arquiteto na elaboração dessas casas provinham de investigações formais, sendo enquadradas no termo que Eisenman cunhou de "cardboard architecture" (LUCENA, 2010, p. 57), "arquitetura de papelão." Tal nome se deve ao fato dos projetos se "concretizarem", majoritariamente, apenas como modelos, maquetes.

A arquitetura de papelão levanta a questão não só para o processo projetual - destacando o seu desenvolvimento em detrimento do resultado final, na defesa de que a construção de um edifício é apenas consequência do projeto arquitetônico -, como também para o discurso de que a maquete ou o desenho já são a própria arquitetura, e não peças gráficas de representação; configuram uma maneira de clamar pela autonomia da disciplina. Francisco Lucena resume o conceito de arquitetura de papelão da seguinte maneira:

Cardboard [papelão] muda o nosso entendimento da forma existente, de um contexto estético e funcional para uma concepção da forma como uma marca ou um sistema notacional, da forma como linguagem; [...] A ideia não é a percepção literal da superfície real como cardboard [papelão], mas da estratificação virtual produzida pela configuração particular do processo.

Cardboard [papelão] seria, enfim, a transposição de um conjunto de regras interiores da arquitetura para estruturas sintáticas, no sentido de gerar outra estrutura formal. (LUCENA, 2010, p. 59).

Ressalta-se o termo "plásticas" porque os New York Five não estavam interessados no conteúdo ideológico das vanguardas, sendo ele considerado motivo de crítica do grupo de arquitetos ao Movimento Moderno, pois a arquitetura teria deixado em segundo plano as investigações formais em prol da vontade de transformação social (DELECAVE, 2015). 
Ou seja, em termos da Gramática Gerativa de Noam Chomsky, Eisenman estaria buscando pelas estruturas profundas que regem os elementos independentes da forma arquitetônica (tais como os pilares, as vigas, os planos transparentes e opacos, etc.). Esses componentes do sistema "arquitetura" seriam as estruturas que podem ser combinadas e manipuladas infinitamente através de regras pré-estabelecidas.

No caso da linguagem, de onde Eisenman importa o conceito de estrutura profunda, essas regras consistem em componentes categoriais, responsáveis por atribuir certas funções (no sentido de função sintática de um elemento em uma oração) às estruturas de um enunciado. Jean Dubois e outros (2006, p. 488) exemplificam a estruturação de uma frase da seguinte maneira:

Neg (negação) $+\mathrm{D}$ (determinante) $+\mathrm{N}($ nome) + Aux (auxiliar) $+\mathrm{V}($ verbo $)+\mathrm{D}+\mathrm{N}$

Essa categorização constitui a estrutura profunda da frase, que pode ser manipulada de infinitas maneiras, cuja combinação gera como resultado a sua estrutura superficial. Exemplo:

Neg $+\mathrm{D}+\mathrm{N}+$ Aux $+\mathrm{V}+\mathrm{D}+\mathrm{N}=\mathrm{Não},+\mathrm{o}+$ pai $+\mathrm{ia}+$ ler $+\mathrm{o}+$ jornal
$\mathrm{D}+\mathrm{N}+\mathrm{Neg}+\mathrm{Aux}+\mathrm{V}+\mathrm{D}+\mathrm{N}=\mathrm{O}+$ pai + não $+\mathrm{ia}+$ ler $+\mathrm{o}+$ jornal
$\mathrm{D}+\mathrm{N}+\mathrm{D}+\mathrm{N} \mathrm{Neg}+$ Aux $+\mathrm{V}=\mathrm{O}+$ jornal $+\mathrm{o}+\mathrm{pai}+$ não $+\mathrm{ia}+$ ler

E assim por diante.

Conforme vão sendo deslocadas as estruturas da frase, seu sentido pode ou não ser modificado, mas sua forma final nunca permanece a mesma. Essa forma final, visível em palavras e não por esquemas, é o que se chama de estrutura superficial (DUBOIS et al, 2006). Eisenman não está interessado no aspecto visual e final que suas casas tomam. Sua preocupação consiste em manipular os elementos formadores da arquitetura. E assim como o que dita a formulação de enunciados obedece a regras de base da linguagem, as operações de Eisenman também partem de princípios pré-estabelecidos, sendo eles adição, subtração, repetição, rotação, etc.

Para esse processo, o diagrama é de suma importância, pois permite o estudo das estruturas profundas ao operar como ferramenta analítica que possibilita a manipulação dos elementos arquitetônicos apenas enquanto forma, esvaziados de significados - como visto no exemplo das diferentes orações, a mudança no arranjo de estruturas pode gerar um significado diferente para o enunciado, mas Eisenman não está preocupado com "a forma final a ser alcançada". Outra grande propriedade do diagrama está no ato de libertar a forma da ideia de presença de um objeto (LUCENA, 2010, p. 63). Isto é, ele aproxima a arquitetura da arte quanto à inexistência de uma demanda externa, permitindo que a disciplina possa manifestar-se por si só através da proposição gráfica do diagrama, uma vez que ele se apresenta como o próprio objeto. 
Figura 1: Diagrama de manipulação das "estruturas profundas" de House III, Lakeville, 1969-1971.
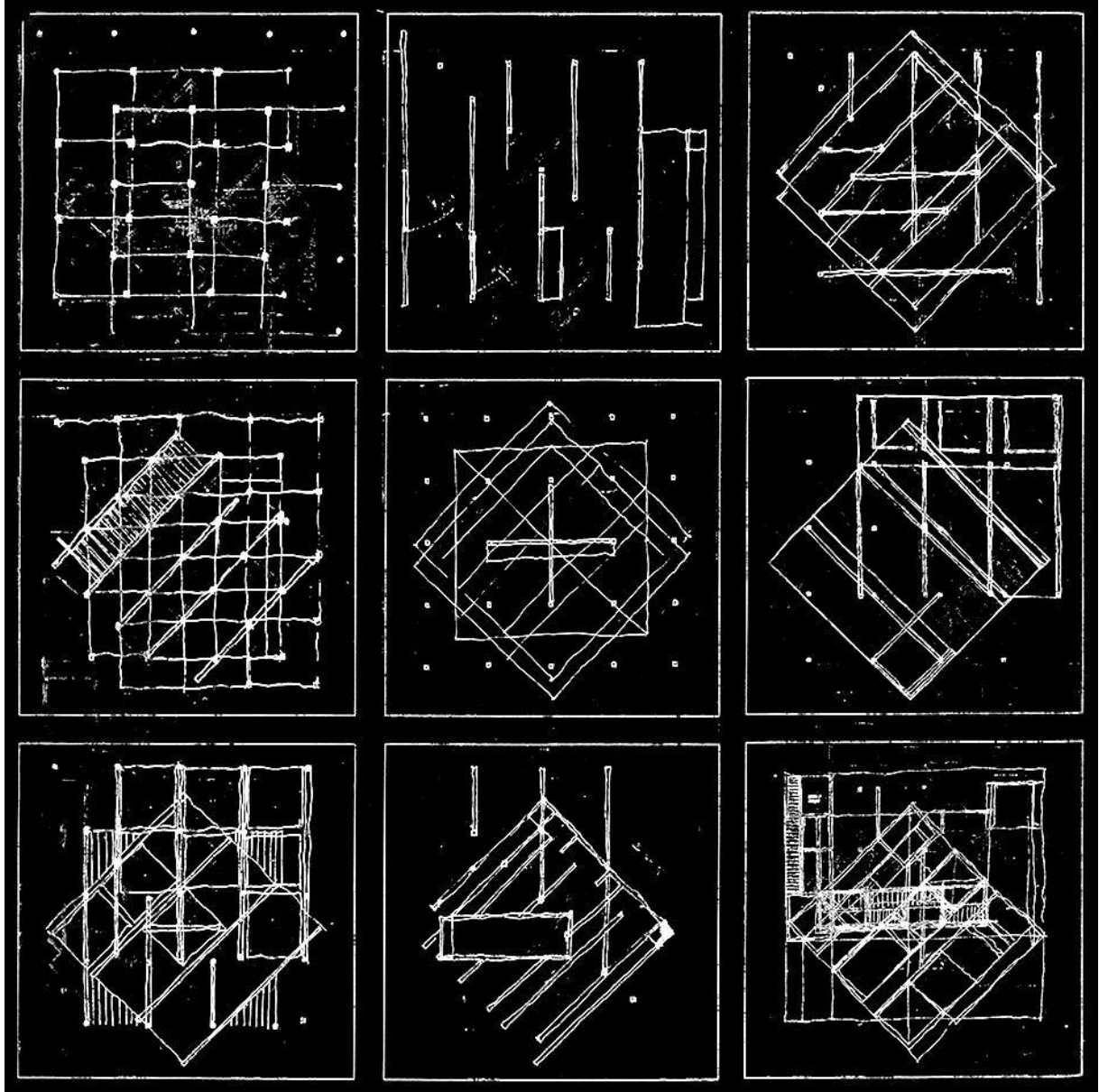

Fonte: https://eisenmanarchitects.com/House-III-1971

Figura 2: Exterior, ou "estrutura superficial", de House III, Lakeville, 1969-1971.

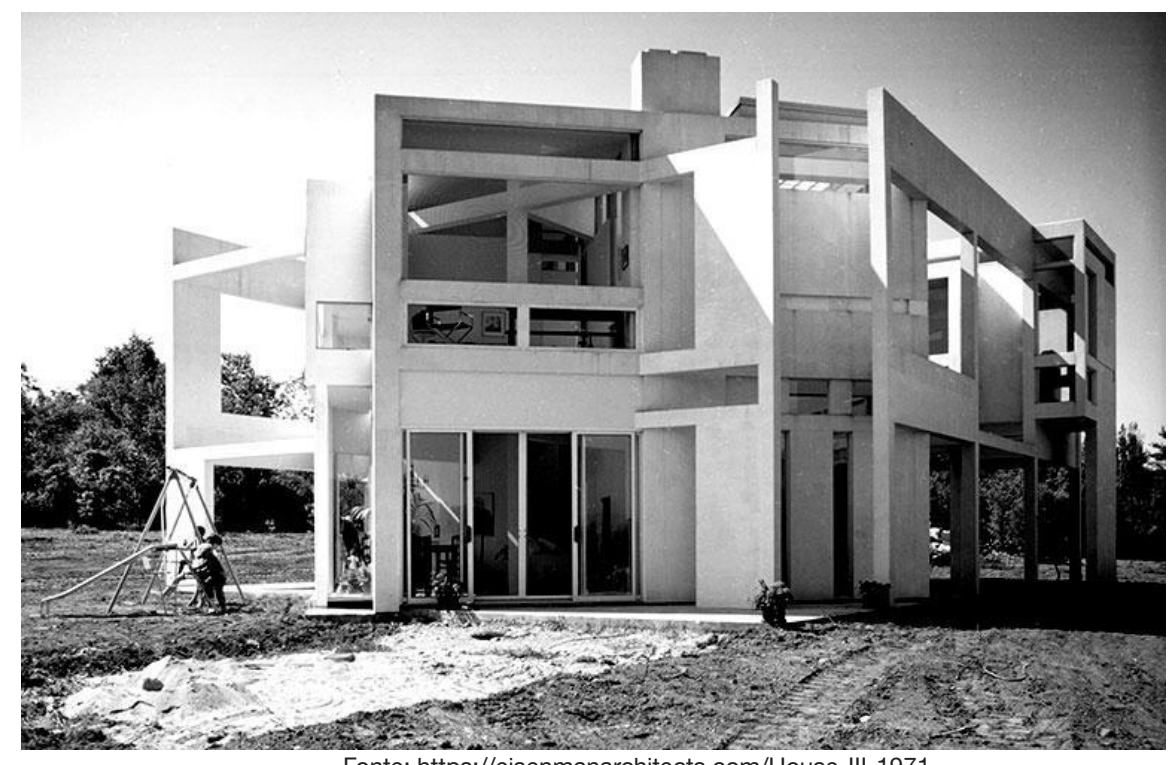

Fonte: https://eisenmanarchitects.com/House-III-1971 
Dessa maneira, pode-se dizer que os diagramas das casas de Eisenman promovem autonomia, ou mesmo uma tautologia, da arquitetura, ao denotar sua "condição artística" (KOSUTH, 1969, p. 220) através de uma linguagem de códigos que Joseph Kosuth (1969, p. 220) chamou de "privados." E isso seria apenas uma consequência da liberdade morfológica do artista com sua obra. Nesse caso, do arquiteto com seu projeto.

Mostra-se, então, a clara aproximação com arte conceitual. Passaro (2009) apresenta a nítida influência de artistas dos anos de 1960 nas reflexões e nos escritos de Eisenman (que só futuramente teriam frutos em projetos). Tal rebatimento mostra-se presente na formulação dos 15 pontos do arquiteto em "Notes on conceptual architecture", de 1970, expostos em formato de notas de rodapé redirecionando o leitor a textos e obras já canonizados como componentes da arte conceitual -, claramente inspirados - ou "ideologicamente plagiados", como diz Passaro (2009, p. 140) - na publicação "Sentences on conceptual art" de Sol LeWitt, de 1969.

Assim como as frases de LeWitt operam aos moldes de instruções para o propositor e o participador de arte conceitual, com destaque para os mecanismo mentais na produção da mesma, as notas de Eisenman também possuem intuito equivalente. A principal motivação do arquiteto está na contestação da arquitetura vigente, que se tornava cada vez mais comercializada pelo seu apelo imagético, tal qual era a arte conceitual na sua tentativa de quebrar os paradigmas tradicionais da visualidade do objeto artístico (BUCHLOH, 1990, p. 107).

Mediante à produção de uma arquitetura mais complexa, cujo foco está em seus processos e não em seu resultado, retira-se (ou, ao menos, diminui-se) seu caráter de mercadoria, levando, inclusive, ao desconforto. Ainda que os projetos de Eisenman fossem sempre acompanhados de textos e vice e versa, o público possuía grandes dificuldades em sua compreensão, situação explícita na fala do arquiteto Robert Stern, na qual declara "para ser generoso, muito do que Eisenman escreve me dá dores de cabeça tanto quanto seus desenhos isométricos" (STERN apud PASSARO, 2009, p. 149). ${ }^{2}$ Nesses trabalhos de Eisenman, há o deslocamento do valor que era dado ao produto final para o seu desenvolvimento, a sua concepção.

Hays (2010, p. 56) acredita que, através dessas operações complexas de aporte conceitual e linguístico, o arquiteto estava à procura de uma etiologia da disciplina, que, em outras palavras, estaria visando a compreensão dos seus processos formativos. Esse momento, que vai da década de 1960 até metade dos anos 1970 na cronologia de Eisenman, era de uma investigação puramente formal - o que não quer dizer que eram de caráter compositivo, ao contrario, pois o foco é lançado para o desenvolvimento formal independente de seu resultado -, partindo de relações fundamentalmente estruturais e internas da arquitetura. $O$ interesse sempre foi a busca por libertar a arquitetura de demandas externas, sejam elas função, cliente, ou mesmo execução.

\section{Transição}

A procura de Peter Eisenman pela absoluta interioridade arquitetônica encontraria outros rumos após seu contato com teóricos pós-estruturalistas, tais como Michel Foucault, Gilles Deleuze, Felix Guattari, Jacques Derrida e Jean Baudrillard, fazendo com que o arquiteto passe a ver como irredutível e aporética a sua busca pelas origens formais da arquitetura (HAYS, 2010, p. 52), presente nas Houses de I a X (1967 - 1975). Essa descrença é motivada, sobretudo, pelos escritos de Derrida e Baudrillard, que auxiliam na argumentação de Eisenman sobre a visão da história como ficção, reflexão presente em seu famoso (e controverso) ensaio de 1984, "O fim do clássico: o fim do começo, o fim do fim", em que alega que a arquitetura nunca abandonou os valores da Antiguidade Clássica. Para Eisenman, a arquitetura produzida desde o Renascimento não passou de uma "simulação" (EISENMAN, 1984, p. 234), o que fazia dela uma representação dos valores clássicos.

Partindo desse pensamento cético, o interesse de Peter Eisenman desloca-se para a procura do que a arquitetura não pode ser, o que caracterizou como "estruturas de ausência" (EISENMAN, 1984, p. 242). Sendo assim, ao invés de buscar por uma origem dentro da própria arquitetura (suas estrutura profundas), excluindo as interferências externas, Eisenman passa a reconhecer a importância de elementos contextuais, majoritariamente ausentes como objetos físicos, mas que são determinantes

\footnotetext{
2 STERN, Robert. Five on Five, Stopin' at the Savoye. Architectural Forum, Boston, v. 138, n. 4, p. 46-57, may 1973.
} 
da forma, que seriam a história, a memória e as pré-existências dos locais para onde pensa seus projetos.

Porém, ele utiliza de elementos externos para chamar atenção para o caráter de arbitrariedade desse processo gerador. Em outras palavras, o arquiteto incorpora a história das cidades para onde planeja seus projetos, mas a toma como algo fictício, através, principalmente, de partes ausentes dos contextos urbanos. A ausência é de suma importância, visto que é a partir de componentes faltantes das cidades, tais como intervenções não construídas, fragmentos de estruturas já destruídas, ou mesmo personagens do local, que o arquiteto traça suas narrativas, configurando-se formalmente nos projetos da série intitulada Cidades de Escavação Artificial.

A consideração da história como ficção pode ser interpretada como derivação, sobretudo, das novas leituras em torno dos arquivos; da constatação de que todo conhecimento acumulado é moldado, já que parte da escolha dentre o que vai ser apresentado e o que vai ser omitido (SCHWARTZ e COOK, 2009). Se o que se sabe sobre o passado é baseado em um determinado ponto de vista, deixando de lado várias outras informações e relatos, poderia a humanidade acreditar nessas narrativas? Então por que não fazer delas, ou melhor, assumi-las, como algo imaginado e fantasioso?

Portanto, as escavações artificiais de Peter Eisenman estariam jogando com a questão do que Michel Foucault (1969, p. 144) chamou de "a priori histórico." Isto é, elas questionam a condição de realidade dos enunciados. E, pelo mesmo motivo, o arquiteto nomeia esse processo projetual de escavação, baseando-se no termo arqueologia, também de Foucault; não no sentido de exploração geológica, mas sim de designar "o tema geral de uma descrição que interroga o já dito no nível de sua existência" (FOUCAULT, 1969, p. 149). É em cima da "interrogação do já dito" que as Cidades de Escavação Artificial (1978 - 1988) operam.

\section{Memória}

A partir do momento em que Peter Eisenman volta-se para o contexto urbano e sua história, impreterivelmente, está trabalhando com a carga mnemônica do local. Essa nova abordagem do arquiteto é aplicada pela primeira vez em 1978, momento do projeto para o bairro do Cannaregio, em Veneza, na ocasião do seminário internacional para a discussão de um plano de habitação popular para a região. No entanto, o termo "memória" ainda não é intensamente explorado em seus textos referentes a esse projeto. Apenas entre 1981 e 1983, para a elaboração do segundo projeto das Cidades de Escavação Artificial, quando da reconstrução das áreas destruídas pela Segunda Guerra Mundial em Berlim, que o vocábulo passa a ser efetivamente a base de suas produções textuais, e consequentes rebatimentos em projeto.

A regeneração urbana da capital alemã ocidental (à época, o país ainda estava bipartido), foi organizada pela edição de 1984 da Exposição Internacional da Construção de Berlim (IBA, proveniente do seu nome em alemão, Internationale Bauausstellung Berlin). O evento contou com a participação de vários arquitetos protagonistas da cena crítica arquitetônica da época, o que Laís Bronstein (2004) aponta como a grande oportunidade de pôr em prática a densa elaboração teórica do período pós-moderno.

Segundo Josef Kleihues (1991), diretor do setor Neubau da IBA, o evento pretendia conferir individualidade à cidade de Berlim, por meio de uma "reconstrução crítica da cidade [...] com base em um confronto racional com os [seus] elementos constituintes" (KLEIHUES, 1991, p. 6, tradução nossa). Ou seja, o incentivo à reconstrução e à criação de novos edifícios de modo a possuírem um caráter singular, a "pluralidade na totalidade" (BRONSTEIN, 2004, p. 6), mas sem deixar de lado as implicações da cidade existente. Era uma maneira, portanto, de opor-se ao preceito de tábula rasa aplicado pelo urbanismo moderno, que, além disso, implicava em cidades habitadas por "máquinas", e não por seres vivos.

Dentre os demais participantes da exposição, o escritório Eisenman/Robertson Architects foi convidado a participar do concurso para o projeto do bloco 5 das áreas específicas de Kochstraße e Friedrichstraße, vindo a possuir a proposta vencedora. A região selecionada para o conjunto 
habitacional encontra-se no distrito de Friedrichstadt, próximo à intercessão com o Muro de Berlim, o que possibilitou um campo fértil para os "sítios arqueológicos" de Eisenman.

A carga de degradação do local, oriunda, sobretudo, do passado traumático de Berlim, é apropriada por Peter Eisenman e Jaquelin Robertson a partir das ausências, dos vazios deixados pelas duas Grandes Guerras. Os arquitetos entendem como "vazio" não só as destruições físicas ocasionadas pelos confrontos bélicos na cidade, como também o buraco causado pelas guerras em sua história (EISENMAN e ROBERTSON, 1983).

Segundo os arquitetos, no caso de Berlim, a cidade em si é o próprio vácuo, pois a Segunda Guerra Mundial teria determinado o fim de sua história e dos valores iluministas (EISENMAN e ROBERTSON, 1983), tão marcantes em seu traçado urbano. Sendo assim, a capital alemã é colocada numa posição de cidade-museu, circundada pelo Muro, evidenciando sua história interrompida (EISENMAN e ROBERTSON, 1983).

Aqui, aliado ao conceito de memória, passa a ser utilizado também o de "anti-memória." Com esse novo termo, os arquitetos pretendem distanciar o caráter mnemônico da cidade de uma carga sentimental ou saudosista. Tal colocação compõe uma forte crítica à arquitetura pós-moderna, por Eisenman e Robertson acreditarem que ela se apropriou dos centros históricos das cidades como objetos de fetiche, reduzindo a história a uma condição de nostalgia (EISENMAN e ROBERTSON, 1983).

Ambos defendem, na apresentação do projeto, que a memória estaria relacionada ao obscurecimento da realidade do presente, voltando-se de modo melancólico e saudoso para o passado, por meio da "tentativa de negação do Muro de Berlim, na intenção de restaurar algum lugar do passado" (EISENMAN e ROBERTSON, 1983, p. 92, tradução nossa). Já a antimemória faria o mesmo com a realidade do passado, "que é, de fato, o que torna a realidade até o presente nenhum lugar - para criar um outro lugar, algum lugar" (EISENMAN e ROBERTSON, 1983, p. 92, tradução nossa). A anti-memória reconhece o esvaziamento dos valores e funções das formas do passado, mas ainda sim reconhecendo sua existência e importância. Pode-se dizer que é uma maneira de contrapor à tábula rasa modernista, ao mesmo tempo que não cai na vã nostalgia pós-modernista.

Projetualmente, a utilização da anti-memória dá-se pela apropriação de elementos marcantes da Berlim Ocidental para daí transformá-los em grids que estruturam a organização do projeto. E são eles: os muros fundadores da capital, ainda como pertencente ao Reino da Prússia, datados do século XVIII; os muros da cidade no século XIX, já como Império Alemão unificado; o próprio Muro de Berlim; e a malha do globo terrestre, conhecida como projeção de Mercator, bolada pelo geógrafo Gerardus Mercator no século XVI, quando a cidade ainda compunha o Sacro Império Romano-Germânico.

A projeção de Mercator é o auge da demonstração de arbitrariedade aplicado ao projeto, pois insere à malha da cidade um elemento externo. Ele não é particular da cidade, mas a liga ao mundo, expondo uma crítica à perda de singularidade e identidade da cidade pelos processos capitalistas. A malha de Mercator nada mais é do que "um padrão genérico universal sem história, lugar ou especificidade" (EISENMAN e ROBERTSON, 1983, p. 92, tradução nossa), que evidencia a perda de "especificidade e identidade [que] foram sacrificadas no altar da história moderna." (EISENMAN e ROBERTSON, 1983, p. 92, tradução nossa).

Os arquitetos, então, "tridimencionalizam" a projeção de Mercator até atingir a altura do Muro subvertendo a lógica do grid, ao passo que este é comumente associado à malha viária, não às edificações (EISENMAN e ROBERTSON, 1983) - e a sobrepõem às outras três malhas, proveniente da continuação dos antigos muros e do atual. É dessa maneira que se extrai a forma do edifício, seus percursos, suas fachadas, expondo as camadas históricas e mnemônicas da cidade logo ao lado de um grande símbolo da guerra, da destruição e da divisão por ela sofrida: o Muro de Berlim. De acordo com Hays (2010), a intenção de Eisenman e Robertson é levar o grid ao esgotamento de suas sobreposições, uma explícita atitude de dificultar sua leitura e romper com a "comodidade visual" (HAYS, 2010, p. 68, tradução nossa) que fez da arquitetura uma mercadoria. 
Figura 3: Desenho com sobreposição das malhas utilizadas para a concepção do projeto para o bloco 5, Berlim, 1981-1985.

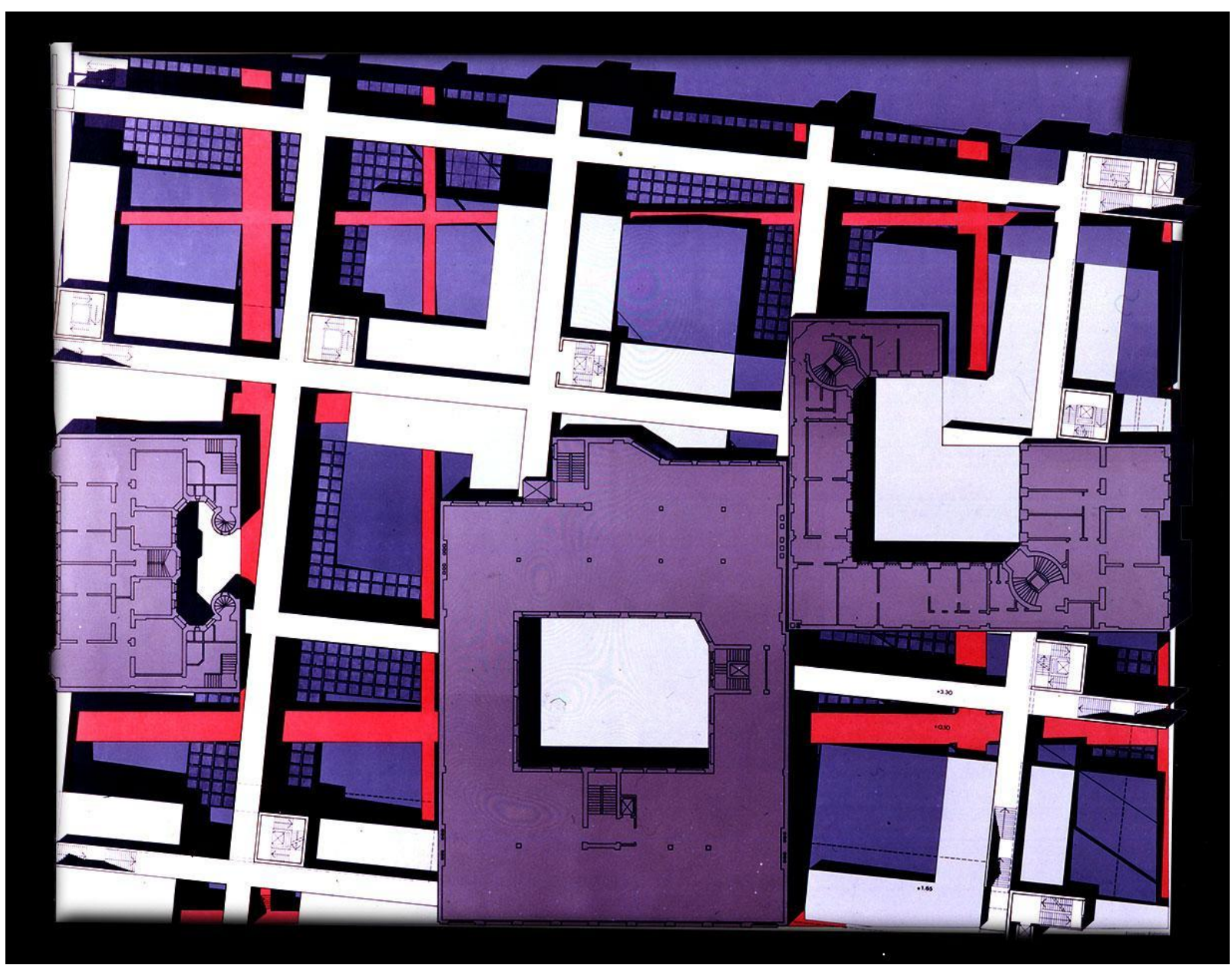

Fonte: https://eisenmanarchitects.com/IBA-Social-Housing-1985

Figura 4: Detalhe da fachada do edifício para o bloco 5, Berlim, 1981-1985.

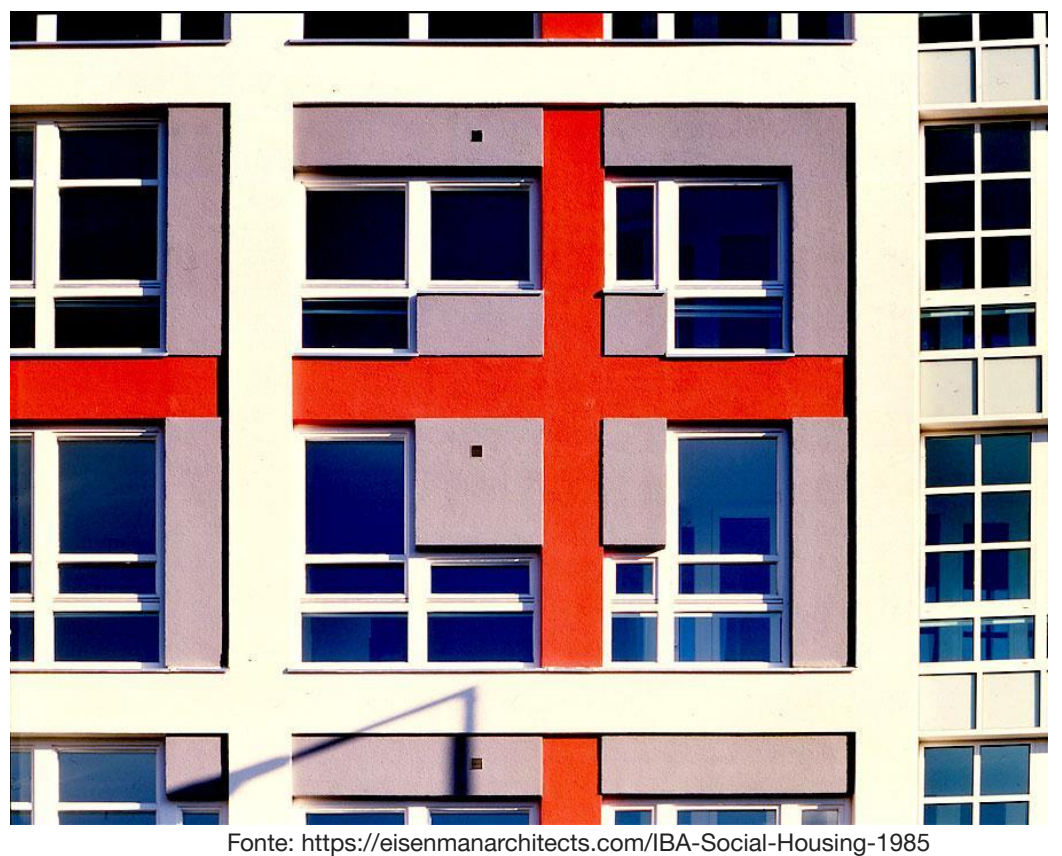


Figura 5: Perspectiva das varandas e caminhos sugeridos pelo projeto, tridimencionalizando os grids sobrepostos das camadas mnemônicas de Berlim, Berlim, 1981-1985.

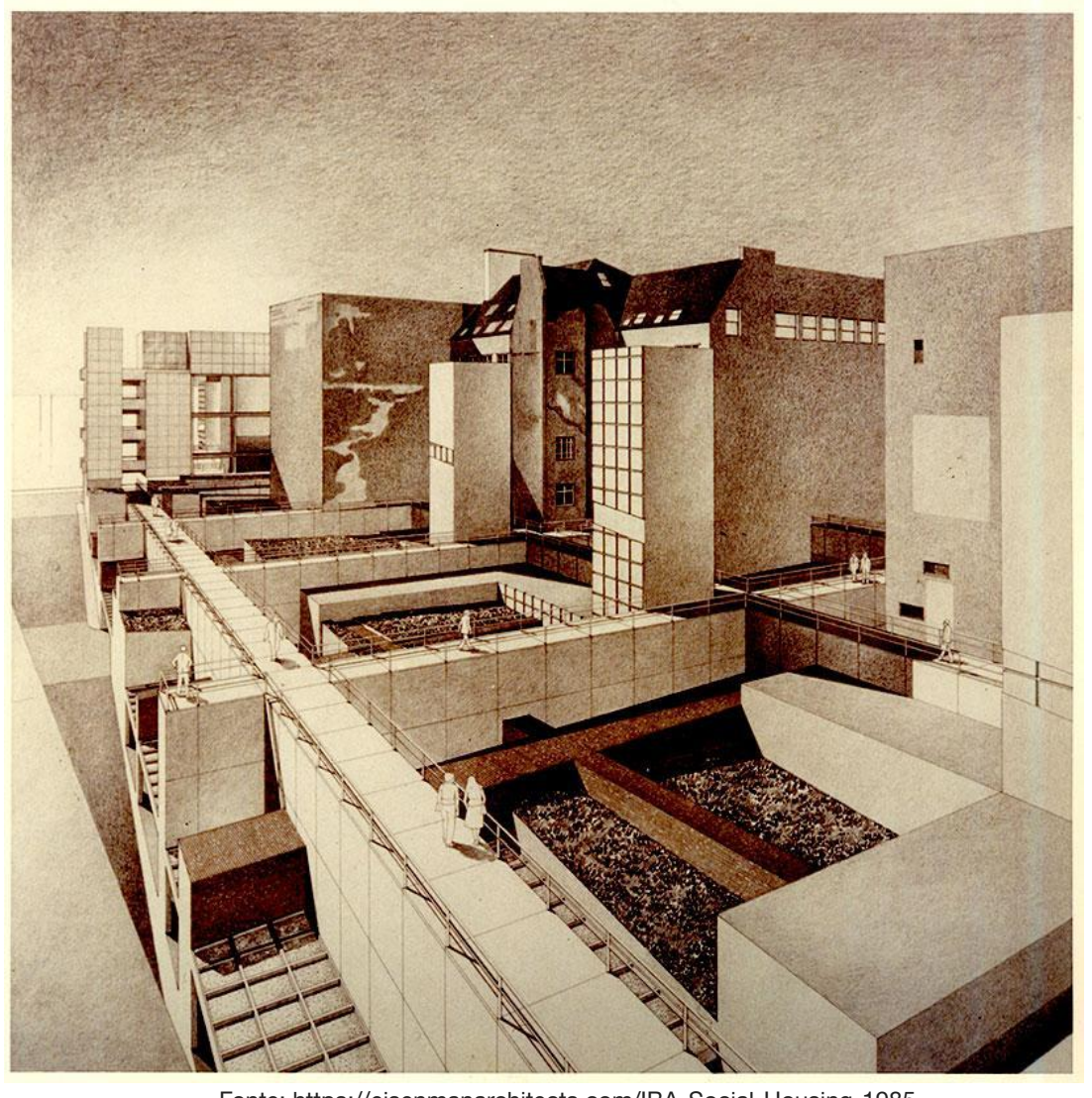

Fonte: https://eisenmanarchitects.com/IBA-Social-Housing-1985

Esse projeto, em específico, foi efetivamente construído - ainda que não em sua completude - em contraposto a uma forte característica dos demais que compõem o restante das Cidades de Escavação Artificial: a lógica da virtualidade, da sua existência apenas no plano narrativo e do desenho. Por isso, carga fictícia e artificial dessa série é tão forte, posto que, para além de jogar com o passado das cidades, Eisenman também está afirmando o desenho como "o veículo da imaginação, da simbolização e auto reflexão da arquitetura, análogo à escrita para a linguagem; o desenho é talvez o mediador necessário da arquitetura crítica" (HAYS, 2010, p. 63, tradução nossa), assumindo a ficção como uma ferramenta para se alcançar a autonomia.

Retornando à superposição de grids, situação em que a camada superior dificulta a leitura da inferior e assim sucessivamente, levanta-se a questão de que ficam, de certo modo, gravados no tecido urbano, como espécies de cicatrizes que mostram os fragmentos de uma cidade anterior, similar ao Bloco Mágico - dispositivo composto por três camadas e que Sigmund Freud (1925) associa ao aparelho psíquico perceptivo humano, em que a camada mais inferior é composta por uma tábua de cera, sobreposta por uma película de papel encerado, que por sua vez se encontra abaixo de uma película de celulóide. Com esse aparato, é possível escrever e apagar facilmente em sua superfície, mas o registro não se apaga por completo, já que deixa seu traçado na tábua de cera. Segundo Freud (1925), a "tábua de cera" de nosso aparelho psíquico é a responsável por armazenar nossas lembranças duradouras, enquanto o "papel encerado" é aquele que acolhe os estímulos que recebemos diariamente; e a "celulose" seria apenas um protetor de todo este dispositivo psíquico.

Em outras palavras, Peter Eisenman e Jaquelin Robertson estão operando com os traços deixados na cidade, o equivalente ao registro que fica marcado na tábua de cera, na camada mais profunda do aparato freudiano mesmo quando a inscrição na camada mais superficial é apagada, não é mais visível no plano externo da cidade. 
Isso quer dizer que Eisenman e Robertson, por meio dessas operações de escavação artificial, recuperam os registros que são imperceptíveis superficialmente em Berlim, mas que se encontram como marcas deixadas no passado e são trazidas à tona pelo projeto. Contudo, sua ação de sobreposição dos "arquivos" existentes, no que se refere aos fragmentos da cidade, produz um novo arquivo, pois abstrai o significado dos elementos utilizados para aplicá-los apenas como significantes (linguisticamente falando) esvaziados (HAYS, 2010), gerando um novo sentido para a forma final. Acaba sendo um arquivamento da cidade, pela recuperação de seus antigos "arquivos", mas que, por fim, gera um outro arquivo - independente, mas, mesmo assim, relacionado à história de Berlim.

\section{Considerações finais}

A trajetória crítica e prática de Peter Eisenman mostra o deslocamento de uma postura completamente autocentrada no objeto arquitetônico, aproximando-o de um objeto de arte, para uma mais atenta às condições externas, inaugurada pelos projetos das Cidades de Escavação Artificial. Tal desvio desemboca, posteriormente, na grande sensibilidade aplicada ao trabalho do Memorial de Berlim aos Judeus Mortos da Europa, de 2005, que também possui o grid como principal articulador formal, mas cuja racionalidade é subvertida pela disposição dos blocos de concreto e as ambiências geradas em seus entremeios.

O reconhecimento de uma fase embrionária de projetos embasados no conteúdo mnemônico urbano - caso das escavações artificiais - levou o arquiteto, historiador e filósofo catalão Ignasi de Solà-Morales (1995), em um ensaio no qual classifica o trabalho de Peter Eisenman em três diferentes momentos até a década de 1990, a chamar esta fase do arquiteto de "memória" (SOLÀ-MORALES, 1995, p. 22). Com tal nomenclatura, Solà-Morales contrapõe as escavações artificiais de Eisenman às suas discussões iniciais, entre os anos de 1967 e 1975, que eram de essência morfológica, como já previamente mencionado, período que o historiador nomeou de "forma" (SOLÀ-MORALES, 1995, p. 22).

Do referido ensaio surge o título do presente artigo, na intenção de expor os enfoques formal e memorial destes momentos da carreira de Peter Eisenman, que englobam da década de 1960 à de 1980, período em que a intensa discussão puramente teórica, mesmo que com rebatimentos em projetos, mas ainda de cunho fortemente especulativo, passa a incorporar questões da cidade. No entanto, a atuação do arquiteto foge de um possível conformismo com a realidade dessas cidades. No caso de Berlim, Eisenman traz à tona cicatrizes de uma cidade que sofreu muito com as Grandes Guerras que se sucederam. Tal atitude não possui o caráter de nostalgia porque desvela a dor encoberta por novas construções na tentativa de preencher o vazio produzido na capital alemã.

Se comparados com a frieza de sua arquitetura de papelão, os projetos para as Cidades de Escavação Artificial, especialmente o de Berlim, garantem, sim, maior sensibilidade à arquitetura de Eisenman. Contudo, esse gesto não é reconfortante para quem o observa. O Bloco 5 é a eterna lembrança de toda a destruição que ali tomou lugar. O desconforto também se repete a menos de dez quadras dali, no Memorial.

Então, apesar da incorporação elementos externos ao objeto arquitetônico, da sua inserção ao contexto e à memória da cidade, Peter Eisenman ainda está provocando um afastamento do observador/usuário da sua arquitetura em vez de aproximá-lo, na medida em que concretiza a dor e, essa sim é aproximada para o presente. Trata-se de uma aproximação com intenção oposta à que seria do aconchego, pois pretende o desconforto da eterna lembrança. Essa aproximação forçada produz o reflexo do distanciamento, similar ao efeito de estranhamento gerado pela aplicação de estruturas profundas para a concepção de suas casas.

O que talvez seja a principal diferença entre o efeito gerado pelas casas produzidas através de recursos da linguística e as escavações artificiais é que o projeto de escavação (no caso deste artigo, o de Berlim) chama atenção para o ato processual da cidade, do lugar onde ele se estabelece, que por sinal, faz parte da sua concepção enquanto arquitetura, expondo no edifício as cicatrizes e traumas daquele sítio e de sua população; e não da autorreflexão do objeto isolado, flutuante. Essa distinção só existe devido à conexão da arquitetura com a cidade. Ou seja, Eisenman continua ressaltando o esforço intelectual por detrás da arquitetura em vez de sua exposição como imagem, mas, desta vez, conjugada à forma, à história e à memória urbanas. 
Sendo assim, mesmo a sua interioridade - buscada através da virtualidade e do caráter fictício da arquitetura, da negação da disciplina como condição de representação do real ao criar seu próprio cosmos baseado no virtual para atingir a autonomia da arquitetura - está relacionada com o seu exterior, a cidade.

\section{Post scriptum}

O presente artigo abordou o conceito de "anti-memória", elaborado por Peter Eisenman e Jaquelin Robertson, de maneira a salientar sua condição de memória não nostálgica e, portanto, desconfortável. Contudo, seu papel no projeto possui dimensões psicanalíticas muito mais intensas do que o que foi tratado neste estudo. Sua articulação com as teorias de Freud, que foram brevemente tratadas aqui pela comparação com o bloco mágico, e também de Derrida a partir das implicações do virtual no aparelho psíquico, possui grande impacto na análise do tecido urbano feita pelos arquitetos. Como a intenção deste trabalho era marcar as diferenças entre duas das fases da obra de Eisenman, mostrar a transição entre elas e, por fim reaproximá-las, não foi dada maior profundidade às questões provenientes da área da psicanálise presentes no projeto para o Bloco 5 de de Koch-/Friedrichstraße para a IBA de Berlim.

\section{Agradecimentos}

Agradeço à Coordenação de Aperfeiçoamento de Pessoal de Nível Superior (CAPES) pelo financiamento da presente pesquisa.

\section{Referências}

BRONSTEIN, Laís. The city of criticism to the modern movement. In: INTERNATIONAL PLANNING HISTORY SOCIETY, 11., 2004, Barcelona. Anais [...]. Barcelona: Universitat de Barcelona, 2004. p. $1-12$.

BUCHLOH, Benjamin. Conceptual art 1962-1969: from the aesthetic of administration to the critique of institutions. October, Cambridge, v. 55, p. 105-143, winter 1990.

COLQUHOUN, Alan. Uma maneira de ver a presente situação [1983]. In: Modernidade e tradição clássica. Ensaios sobre arquitetura. $1^{\text {a }}$ ed. São Paulo: Cosac \& Naify, 2004. p. 185-190.

DELECAVE, Jonas. Em busca de uma autonomia disciplinar: John Hejduk e o ensino de arquitetura na Cooper Union, 1964 - 1971. 2015. Dissertação (Mestrado em Arquitetura) - Universidade Federal do Rio de Janeiro, Rio de Janeiro, 2015.

DUBOIS, Jean; GIACOMO, Mathée; GUESPIN, Louis; MARCELLESI, Christiane; MARSELLESI, Jean-Baptiste; MEVEL, Jean-Pierre. Dicionário de linguística. São Paulo: Cultrix, 2006.

EISENMAN, Peter. O fim do clássico: o fim do começo, o fim do fim [1984]. In: NESBITT, Kate (org.). Uma nova agenda para a arquitetura: antologia teórica (1965-1995). São Paulo: Cosac \& Naify, 2006. p. 233-252.

EISENMAN, Peter; ROBERTSON, Jaquelin. Koch/Friedrichstrasse, block 5. Architectural design, v. 53, n. 9, p. 91-93, London, jan. 1983.

FOUCAULT, Michel. O a priori histórico e o arquivo. In: A arqueologia do saber. Rio de Janeiro: Forense Universitária, 2012, p. 143-149. 1969.

FREUD, Sigmund. Nota sobre o bloco mágico [1925]. In: Obras completas. v. 16. São Paulo: Cia das Letras, 2011, p. 241-246.

HAYS, K. Michael. Architecture's desire. Reading the late avant-garde. Cambridge: MIT Press, 2010.

KLEIHUES, Josep Paul. New building areas, buildings and projects. In: Internationale Bauausstellung Berlin 1987 project report. English edition. Berlin: Felgentreff \& Goebel GmbH, 1991. p. 6-9. 
KOSUTH, Josef. A arte depois da filosofia [1969]. In: FERREIRA, Glória; COTRIM, Cecilia (org.). Escritos de artistas: anos 60/70. Rio de Janeiro: Zahar, 2006.

LUCENA, Francisco. Peter Eisenman: autonomia crítica da arquitetura. 2010. Dissertação (Mestrado em História Social da Cultura) - Pontifícia Universidade Católica do Rio de Janeiro, Rio de Janeiro, 2010.

PASSARO, Andrés. Linguística e estruturalismo na arquitetura dos anos 70. In: OLIVEIRA, Beatriz S.; LASSANCE, Guilherme; ROCHA-PEIXOTO, Gustavo; BRONSTEIN, Laís (org.). Leituras em teoria da arquitetura. Rio de Janeiro: Viana \& Mosley, 2009. v. 1, p. 128-161.

SCHWARTZ, Joan; COOK, Terry. Arquivo, Documentos e Poder: A construção da memória moderna. Registro - Revista do Arquivo Público Municipal de Indaiatuba. São Paulo: Fundação Pró-Memória de Indaiatuba, v. 3, n. 3, p. 15-30, jul. 2004.

SOLÀ-MORALES, Ignasi. Forma, memoria, acontecimiento. AV monografías, Madrid, v. 53, n. 2, p. 20-23, mayo/jun. 1995.

\section{Carolina Ferreira de Carvalho}

Graduada em Arquitetura e Urbanismo pela Pontifícia Universidade Católica do Rio de Janeiro (PUC-Rio) (2019), da qual foi bolsista pelo seu desempenho no vestibular, e com experiência profissional em projetos de interiores comerciais, arquitetura rural e editoração gráfica de conteúdos de arquitetura. Atualmente, é bolsista da Coordenação de Aperfeiçoamento de Pessoal de Nível Superior (CAPES) em seu mestrado pelo Programa de Pós-graduação em Arquitetura da Universidade Federal do Rio de Janeiro (PROARQ/FAU/UFRJ), dedicado à pesquisa sobre as interfaces da linguística e da psicanálise com a arquitetura pós-moderna.

Como citar: CARVALHO, Carolina Ferreira de. Da "forma" à "memória". Das casas sem sítio para a cidade como determinante nos projetos de Peter Eisenman. Revista Paranoá, n.31, jul/dez de 2021. DOI: http://doi.org/10.18830/issn.1679-0944.n31.2021.07

Editores responsáveis: Carlos Henrique de Lima e Carolina Pescatori 